\title{
ESCOAMENTO SUPERFICIAL E BALANÇO HÍDRICO EM AMBIENTES SECOS COM TOPOGRAFIA COMPLEXA - BACIA DO RIACHO DO SACO - PERNAMBUCO
}

\author{
Jonas O. P. Souza*
}

Universidade Federal da Paraíba

\section{Antônio C. B. Corrêa**}

Universidade Federal de Pernambuco

Resumo: No Brasil ainda há pouca informação sobre o escoamento em pequenas bacias semiáridas, em especial para bacias que apresentam variações altimétricas relevantes, visto o pouco detalhamento dos dados climáticos. Pensando nisso, o presente trabalho analisou a relação precipitação/escoamento a partir do método do Balanço Hídrico Sequencial Diário, da Bacia do Riacho do Saco, Sertão Central pernambucano. A bacia apresenta relevo complexo com diferença altimétrica de cerca de 700 metros entre a foz (409m) e as cabeceiras (superior a 1.100m), o que reflete diretamente nas características climáticas, em especial na variação da precipitação. Deste modo, o Balanço Hídrico Sequencial Diário foi realizado utilizando dados de quatro PCDs, mapeamento de cobertura da terra e pedológico. Essas informações foram integradas gerando 24 zonas homogêneas de precipitação/solo/cobertura, sendo realizada a análise para cada uma delas. Ao avaliar os resultados, nota-se a importância da zona altimétrica da PCD Triunfo, que, apesar de representar apenas $25,6 \%$ da área da bacia, é responsável por mais de $37 \%$ do volume de água captado pela bacia, alcançando $46,31 \%$ do volume escoado em toda a bacia, sendo assim a principal fonte de captação de água para a bacia. É necessário lembrar que a alta porcentagem de escoamento está diretamente ligada ao uso agrícola indiscriminado e que altas taxas de escoamento levam a perda de água e sedimento para a bacia, e, deste modo, torna-se clara a necessidade do aumento dos níveis de infiltração para que a água seja retida e movimente-se como fluxo de base, prolongando o tempo de permanência na paisagem.

Palavras-chave: Balanço Hídrico Sequencial Diário. Semiárido; CAD máximo.

EVALUATION OF THE EFFECTIVENESS OF PROTECTED AREAS: CONCEPTS, METHODS AND CHALLENGERUNOFF AND WATER BALANCE IN DRYLANDS WITH COMPLEX TOPOGRAPHY - SACO CREEK WATERSHED - PERNAMBUCO

Abstract: In Brazil, there is still lack of data on the runoff small semi-arid basins, especially for basins that present significant altimetric variations, given the lack of detail in the climatic dat. Accordingly this research examined the relationship rain/runoff through Daily Sequential Water Balance methodology, of Saco Creek Watershed, Pernambuco central dryland. The watershed presents a complex relief with altimetric variation of 700 meters between the river mouth $(409 \mathrm{~m})$ and the headwaters (above $1.100 \mathrm{~m}$ ), that directly reflect in the climatic characteristics, principally in the precipitation variation. The daily water balance was performed using four PCD, landcover map and soil map. These three data was integrated creating 24 uniform zones of precipitation/ soil/landcover, and the analysis was undertaken to each one of them. Looking to the results, it is clear the importance of PCD Triunfo altimetric zone, where despite representing only $25,6 \%$ of the watershed it represents for more than $37 \%$ of water volume collect by watershed, $46,31 \%$ of all basin runoff. This area is the main collect water source from watershed. It is necessary to remember that the high runoff percentage is directly tied to widespread agricultural use, and the high runoff rates lead to loss of water and sediment. Therefore, it is clear the necessity to increase the infiltration levels order for the water be retained and move as base flow, prolonging the residence time in the landscape.

Keywords: Daily Sequential Water Balance. Semiarid. Field Capacity.

\section{ESCORRENTÍA SUPERFICIAL Y BALANCE HÍDRICO EN AMBIENTES SECOS CON TOPOGRAFÍA COMPLEJA - CUENCA DEL RIACHO DO SACO - PERNAMBUCO}

Rsumen: En Brasil, todavía hay poca información sobre la escorrentía en pequeñas cuencas semiáridas, especialmente para las cuencas que presentan variaciones altimétricas relevantes, dada la falta de datos climáticos detallados.Pensando en esto, el presente estudio analizó la relación lluvia / escorrentía con basis en el método del balance hídrico. secuencial diario de la cuenca del Riacho do Saco en la región del Central Sertão, Pernambuco . La cuenca presenta un relieve complejo con una diferencia altimétrica de aproximadamente 700 metros entre la desembocadura (409m) y las cabeceras (más de $1100 \mathrm{~m}$ ), que se refleja directamente en las características climáticas, especialmente en la variación de la precipitación. Por lo tanto, el balance hídrico diario se realizó utilizando datos de cuatro PCD, mapeo de la cobertura del suelo y datos pedológicos. Esta información se integró generando 24 zonas homogéneas de precipitación / suelo / cobertura, y se realizó el análisis para cada una de ellas. Al evaluar los resultados, se observa la importancia de la altimetría del PCD Triunfo, que a pesar de representar solo el 25.6\% del área de la cuenca, es responsable de más del $37 \%$ del volumen de agua recolectada por la cuenca, alcanzando el $46.31 \%$ del volumen drenado en toda la cuenca, por lo que es la principal fuente de captación de agua para la cuenca. Es necesario recordar que el alto porcentaje de escorrentía está directamente relacionado con el uso agrícola indiscriminado, y que las altas tasas de escorrentía conducen a la pérdida de agua y sedimento a la cuenca, por lo que se hace evidente la necesidad de aumentar los niveles de infiltración para que el agua sea retenida y se mueva como un flujo de base, prolongando su tiempo de permanencia en el paisaje.

Palabras clave: Balance hídrico secuencial diário; semiárido; CAD máximo.

*Doutor em geografia. Professor Adjunto .Cidade Universitária - João Pessoa/PB. CEP. 58051-900. https://orcid.org/0000-0002-1405-0944: E-mail: jonasgeoufpe@yahoo. com.br

**Doutor em geografia. Professor - Av. Prof. Moraes Rego, 1235 - Cidade Universitária - Recife/PE. CEP. 50670-901. https://orcid.org/0000-0001-9578-7501: E-mail: dbiase2001@terra.com.br 


\section{Introdução}

Nas Terras Secas há a predominância dos rios efêmeros e intermitentes, havendo fluxo de água nos canais apenas durante as precipitações ou estação chuvosa, respectivamente (BIGARELLA; SUGUIO; BECKER, 1979). Estes serão os momentos em que o escoamento superficial irá "abastecer" o canal fluvial, e, deste modo, para entender a dinâmica fluvial é necessário compreender a relação chuva/escoamento (GRAF, 1988), como também analisar a relação magnitude/frequência dos eventos chuva/escoamento, os quais irão controlar as vazões dos canais. 0 entendimento atual aponta para a importância hidrológica e sedimentológica do processo do escoamento superficial nos chamados ambientes "runoff-dominated geomorphic system" (BRACKEN; CROKE, 2007), tal qual os ambientes semiáridos e subúmidos do Nordeste brasileiro. Esses ambientes se diferenciam dos ambientes de hidrologia controlada pela saturação do solo, os ambientes úmidos, sendo o escoamento superficial o controlador da recarga hidrológica dos canais, bem como o controlador dos processos erosivos na encosta. Dessa forma, o escoamento superficial representa a contribuição de massa e energia para o sistema fluvial como um todo, controlando os processos fluviais e os processos de encosta.

Para analisar a relação entre precipitação e escoamento é necessário avaliar o estado da bacia, porque, "se houver uma precipitação sobre a bacia previamente supersaturada, o escoamento será totalmente superficial, não havendo mesmo evaporação se a umidade do ar estiver saturada" (BIGARELLA; SUGUIO; BECKER, 1979, p. 9). A saturação do solo está relacionada com a capacidade de infiltração do mesmo, que é colocada como uma das características que apresentam forte sensitividade, com valores flutuantes relacionados ao uso e à conservação do solo, como também a alterações naturais das características do solo ou da cobertura superficial (LOVELL; JOHNSTON, 2009; GRAF, 1988). A partir dessas mudanças o volume do escoamento superficial é mutável e vai depender do estado do sistema (Burt, 2001), assim o estudo sobre a capacidade de acúmulo de água no solo torna-se essencial não só por ser o fator-chave para a mensuração da saturação e do escoamento, como também por estar diretamente relacionado com o crescimento das plantas e o tipo de vegetação da área (RAMOS; CASANOVAS, 2006).

Entre os fatores relacionados com o escoamento superficial a vegetação/uso pode ser entendida como o fator mais sensitivo, ou seja, mais passível de sofrer modificações, naturais e principalmente antrópicas.
Essas modificações influenciam diretamente 0 escoamento superficial, e desse modo a modificação da distribuição e dos padrões da vegetação pode ser compreendida como variável modificante para o escoamento superficial, principalmente quando a análise trabalhar com o tempo histórico. Assim, analisando as modificações dos padrões e distribuição da vegetação no semiárido pode-se ter indicações da variação do escoamento superficial, e consequentemente da mudança nas fontes de sedimento e das áreas de sedimentação (IMESON; PRINSEN, 2004; KASAI et al., 2005). Normalmente o escoamento aumenta com a retirada da vegetação, relação visível principalmente em bacias de pequeno porte (TUCCl; CLARKE, 1997), que é o caso do presente estudo.

Além das mensurações diretas por fluviômetros ou outros equipamentos/técnicas (RODRIGUES et al., 2013; COSTA et al., 2013), as quais exigem uma maior disponibilidade de recursos, a literatura científica apresenta diversificadas metodologias para o cálculo de escoamento superficial. Uma das metodologias mais utilizadas é a partir de modelos hidrológicos como o Soil and Water Assessment Tool - SWAT - que entre outras informações calcula o escoamento superficial a partir de dados climáticos, de solo e de uso da terra (MACHADO; VETTORAZZI; CRUCIANI, 2003). Outro modelo utilizado é o Modelo Hidrológico Curve Number - MHCN -, baseado em dados morfométricos, de uso e de solo (FEITOSA et al., 2010; BESKOW et al., 2009). Como também a partir do TOPMODEL (LIANG et al., 2012), ou a partir de diversos métodos de balanço hídrico (CHIEW et al., 1995; KARNIELE; ASHER, 1993; FENG; VICO; PORPORATO, 2012).

0 presente estudo visa mensurar o escoamento superficial da Bacia do Riacho do Saco, a qual apresenta um arranjo ambiental complexo, com diferenciações internas de precipitação, tipos de solo e de cobertura. A avaliação da contribuição de cada área de uma bacia para o escoamento/vazão total é importante ao se trabalhar com gerenciamento de recursos hídricos, normalmente sendo realizada a partir da análise de dados de precipitação e vazão (ARAI; PEREIRA; GONÇALVES, 2012; CAYLOR; MANFREDA; ITURBE, 2005), contudo, em bacias sem dados fluviométricos, como é o exemplo de grande parte do semiárido nordestino, há a necessidade do uso de modelagens hidrológicas para a análise. Deste modo, o escoamento será analisado a partir do Balanço Hídrico Sequencial Diário, levando em consideração as diferenciações ambientais e objetivando avaliar a contribuição de cada área ao escoamento superficial total da bacia. 


\section{Materiais e métodos}

A bacia de drenagem do riacho do Saco está situada na microrregião do Pajeú, Sertão Central de Pernambuco, entre os municípios de Serra Talhada e Santa Cruz da Baixa Verde, além de algumas cabeceiras de drenagem nos municípios de Triunfo/PE, Manaíra e São José da Princesa, na Paraíba (Figura 1 - Esquerda), perfazendo uma área de $142,5 \mathrm{~km}^{2}$. Regionalmente, a bacia está inserida na Depressão Sertaneja, e suas cabeceiras de drenagem encontram-se sobre a Encosta Meridional do Planalto da Borborema (CORRÊA et al., 2012), apresentando uma diferença altimétrica de cerca de 700 metros entre a foz $(409 \mathrm{~m})$ e as cabeceiras (superior a $1.100 \mathrm{~m}$ ), apresentando entre estes extremos dois patamares aplainados com altimetrias médias de $600 \mathrm{~m}$ e $800 \mathrm{~m}$, respectivamente, e a transição entre esses patamares dá-se de forma abrupta, respondendo a controles estruturais (Figura 1 - Direita). Corrêa (1997) apontou para a diferenciação da umidade/precipitação em faixas altitudinais, no caso, $500 \mathrm{~m}, 700 \mathrm{~m}, 900 \mathrm{~m}$ e $1.100 \mathrm{~m}$, do maciço da Serra da Baixa Verde - o que se reflete na Bacia do Riacho do Saco. A relação entre orografia e precipitação, apesar de normalmente positiva, é complexa e estritamente relacionada com as características dos ventos dos sistemas sinóticos atuantes, e, quanto maior o número de sistemas sinóticos atuantes, maior a complexidade (COLTON, 1976; CANDIDO; NUNES, 2008). Enquanto que em ambientes planos uma medição de precipitação pode cobrir uma área de $100 \mathrm{~km}^{2}$, em ambientes de topografia irregular/montanhosa a variação de precipitação pode ser grande mesmo em pequenas distâncias, limitando assim a espacialidade dos dados obtidos por medições/ estações pontuais (CORRADINI, 1985).

Figura 1 - Direita - Mapa de localização da Bacia do Riacho do Saco. Esquerda - Patamares e Modelo Digital de Elevação da Bacia do Riacho do Saco.
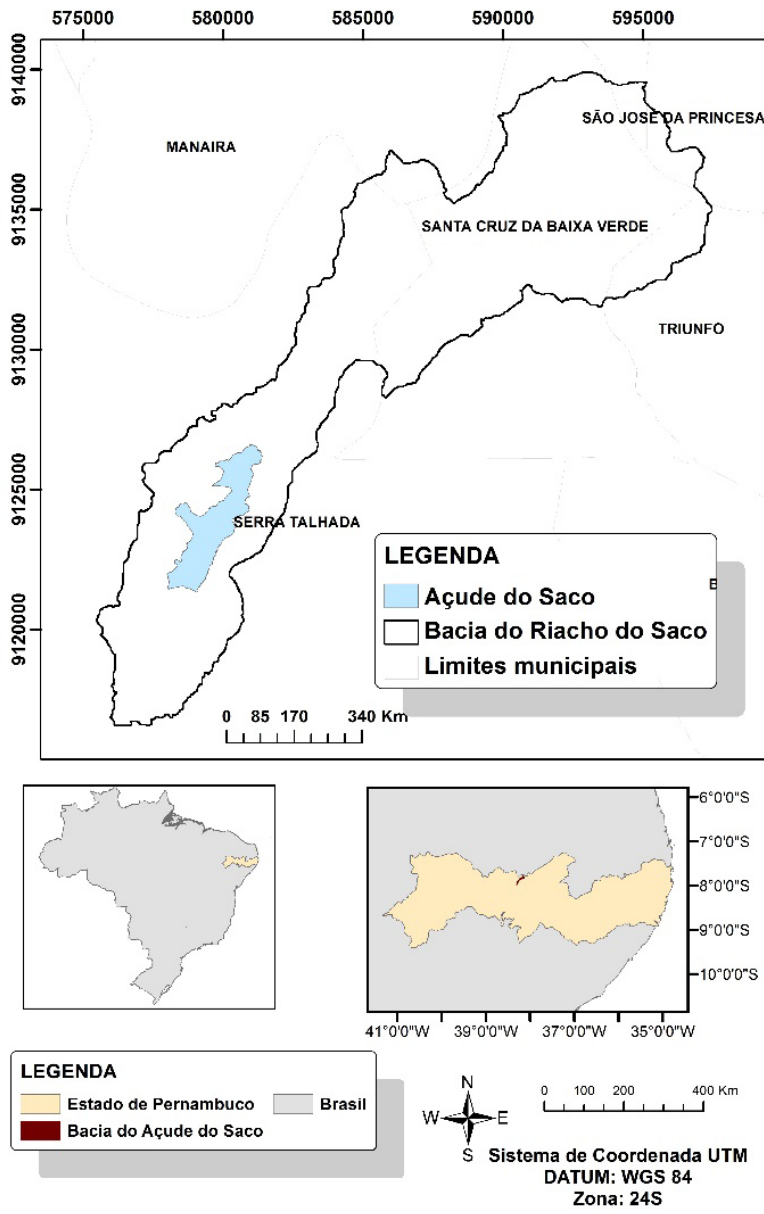
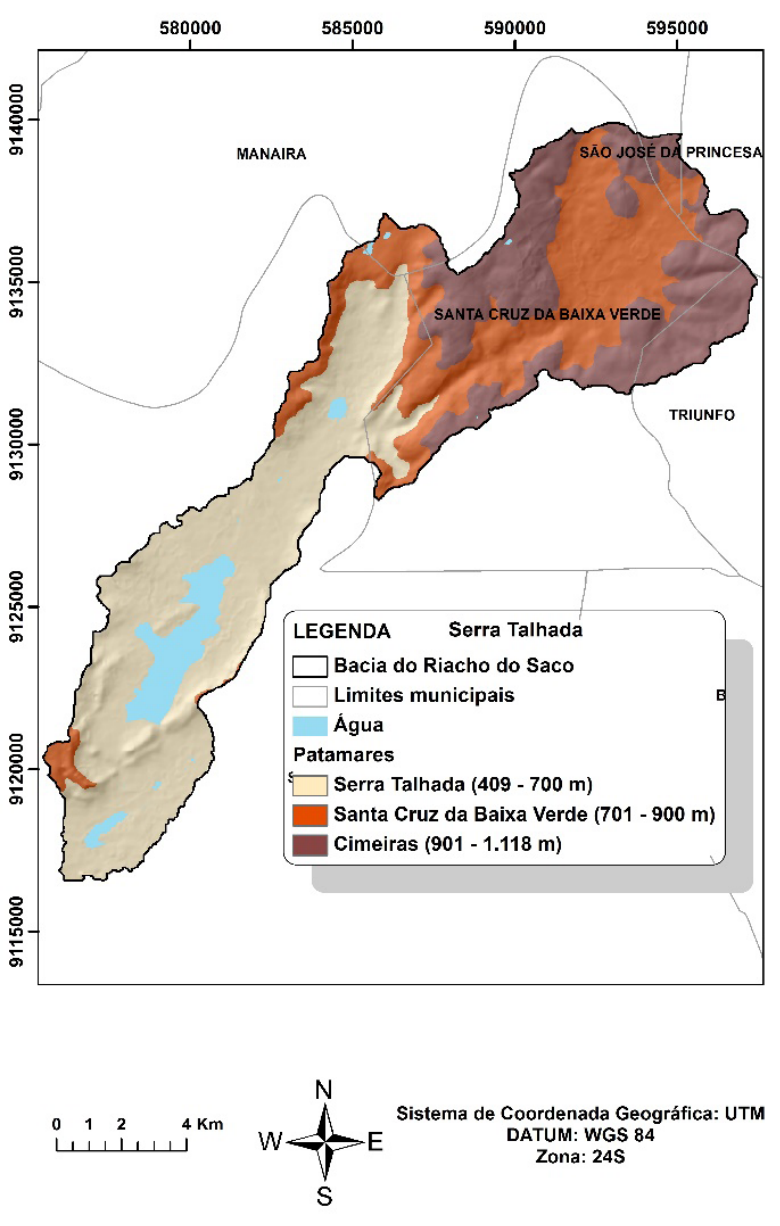
As séries diárias de precipitação foram obtidas a partir de quatro plataformas de coleta de dados (PCDs): duas em Serra Talhada, uma em Santa Cruz da Baixa Verde e uma em Triunfo, e obtidas a partir do projeto Agritempo (Sistema de Monitoramento Agrometeorológico) do Ministério da Agricultura, Pecuária e Abastecimento (Figura 2). Desse modo, encontram-se disponíveis dados de quatro localidades na bacia com diferentes al- timetrias e períodos de observação (Tabela 1). Devido ao período disponível para a PCD Santa Cruz da Baixa Verde, apenas a partir de 2006, a análise será realizada entre o ano de 2006 e o ano de 2012, período com informações disponíveis para as quatro plataformas. Dessa forma, será possível trabalhar com os dados de cada uma, relacionando-os com zonas altimétricas, de forma a englobar toda a área da bacia.

Tabela 1 - Direita - Mapa de localização da Bacia do Riacho do Saco. Esquerda - Patamares e Modelo Digital de Elevação da Bacia do Riacho do Saco.

\section{Altitude Zona altimétrica Área de cobertura de cada PCD}

\begin{tabular}{cccc}
\hline $\begin{array}{c}\text { Serra Talhada - CPTEC } \\
\text { Serra Talhada - } \\
\text { LAMEPE/ITEP }\end{array}$ & $416 \mathrm{~m}$ & $409 \mathrm{~m}-500 \mathrm{~m}$ & $8,40 \%$ \\
$\begin{array}{c}\text { Santa Cruz da Baixa Verde } \\
\text { Triunfo }\end{array}$ & $841 \mathrm{~m}$ & $701 \mathrm{~m}-900 \mathrm{~m}$ & $38,30 \%$ \\
\hline & $1.030 \mathrm{~m}$ & $901 \mathrm{~m}-1.118 \mathrm{~m}$ & $27,70 \%$ \\
\hline
\end{tabular}

Figura 2 - PCDs disponíveis na Bacia do Riacho do Saco.

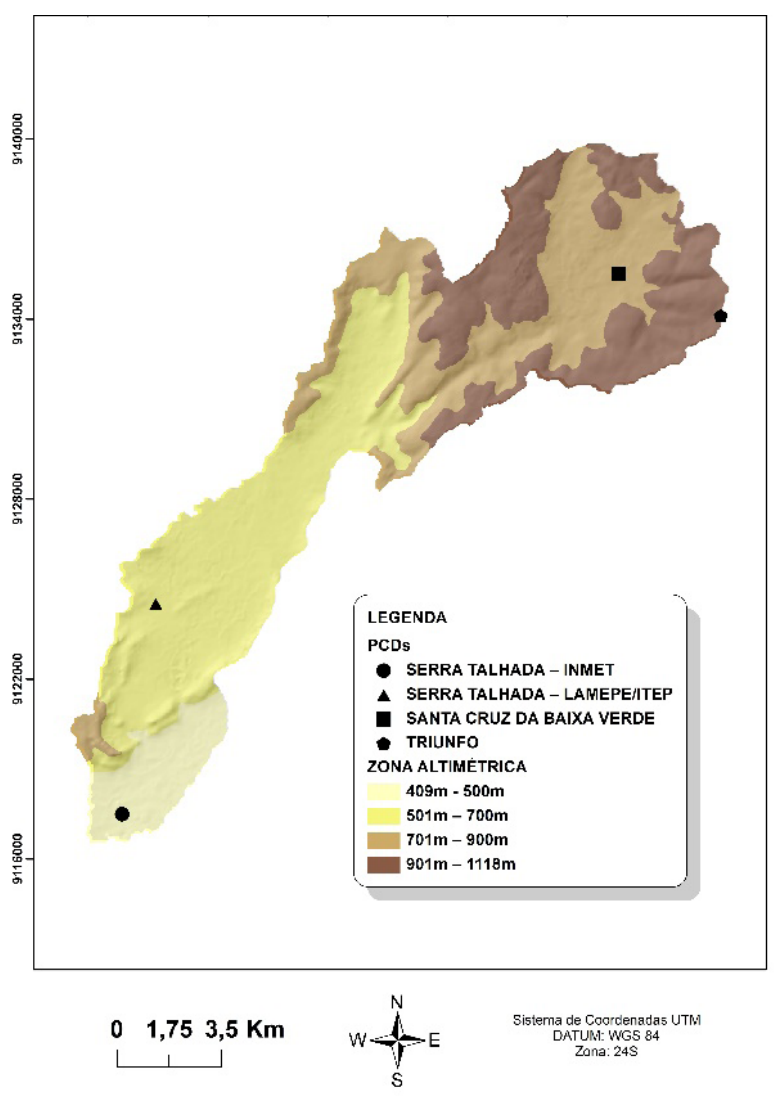


As PCDs fornecem dados diários de precipitação, temperatura máxima, temperatura mínima, evapotranspiração potencial e a disponibilidade de água acumulada no solo. Todavia a medição/cálculo da disponibilidade de água acumulada no solo é realizada a partir de um valor fixo para a capacidade de campo, não sendo adequada para a análise da precipitação excedente em diferentes arranjos de solo e uso/cobertura. Desse modo, para cada arranjo solo/cobertura será utilizada uma capacidade de campo específica.

0 escoamento vai estar diretamente relacionado com a relação precipitação/evapotranspiração e a disponibilidade atual de água no solo, a qual é limitada pela capacidade máxima de armazenamento de água para cada área da bacia (KARNIELE; ASHER, 1993). A capacidade de armazenamento de água do solo está relacionada com a interação da porosidade com a profundidade/sistema radicular do mesmo. Tais características controlariam a infiltração e seriam o principal controle do escoamento no estudo de ambientes secos, assim como a sua variação espacial em uma bacia hidrográfica tem forte efeito no comportamento hidrológico da mesma (MICHAELIDES; WILSON, 2007).

A modelagem do escoamento superficial pode ser baseada em modelos de superação de capacidade de infiltração ou a partir de modelos de superação da saturação do solo (LIANG et al., 2012), ou seja, a partir da superação do limiar da velocidade de infiltração ou da superação do limiar da saturação (armazenagem de água no solo), o qual é o caso do presente trabalho que utilizou a capacidade de campo como limiar de saturação.

Para o presente trabalho será utilizado o Balanço Hídrico Sequencial Diário, no qual o Excedente Hídrico Diário representaria o volume $(\mathrm{mm})$ de escoamento superficial diário, por meio do uso dos dados de precipitação diária, temperatura mensal média e capacidade de armazenamento do solo (CHIEW et al., 1995; KARNIELE; ASHER, 1993). Outros elementos podem ser utilizados, como os valores de percolação profunda, interceptação, derretimento de neve, entre outros (HIGGINS et al., 1988). Iturbe et al. (1999) definem a equação do balanço de umidade do solo a partir da equação:

$$
n Z r \frac{d s}{d t}=I(s, t)-E(s, t)-L(s, t)
$$

Onde $\mathrm{n}$ é a porosidade do solo; $\mathrm{Zr}$ é a profundidade do solo; I (s,t) é a taxa de infiltração; E é a taxa de evapotranspiração; e L é a taxa de percolação profunda.
As interações da água em subsuperfície não serão analisadas, e, deste modo, processos superficiais serão trabalhados como independentes; tal escolha deu-se pela característica de os ambientes secos da água em subsuperfície serem profundos e o fluxo em subsuperfície de pouca relevância para a dinâmica superficial (CAYLOR; MANFREDA; ITURBE, 2005). Ou seja, a capacidade de campo ou capacidade de água no solo é definida pela porosidade do solo e a profundidade da zona radicular do solo (PAN et al., 2013). Os solos foram separados em quatro classes de porosidade média: solos argilosos com $2,0 \mathrm{~mm} / \mathrm{cm}$, solos de textura média com $1,4 \mathrm{~mm} / \mathrm{cm}$ e solos com textura arenosa com 0,6mm/cm (DOORENBOS; KASSAM, 1994). Também foi inserida uma classe para os afloramentos rochosos com $0,2 \mathrm{~mm} / \mathrm{cm}$, os quais se apresentam bastante fraturados e em alguns casos com pequenas camadas de sedimento. Já as profundidades médias para as zonas radiculares foram obtidas a partir da adaptação das profundidades médias para culturas e formações vegetais (ALFONSI et al., 1990).

A escolha do trabalho em escala diária dá-se pela distinção do comportamento hidrológico na área, visto que os modelos anuais ou até mensais poderiam não captar a variação característica dos ambientes secos e com alta taxa de evapotranspiração (FENG; VICO; PORPORATO, 2012). Os eventos de chuva serão idealizados como uma série de eventos pontuais, ou seja, cada dado diário será considerado uma chuva individual de ocorrência instantânea, sendo ignorada deste modo a dimensão temporal das precipitações, assim como a intensidade da chuva e da velocidade de infiltração (ITURBE et al., 1999).

Ao mesmo tempo, cada zona homogênea de classe de solo/tipo de uso estará submetida a condições de precipitação e temperatura diferentes, dentro das quatro zonas altimétricas da bacia anteriormente mencionadas. Portanto, o presente trabalho irá relacionar as áreas homogêneas de capacidade máxima de armazenamento de água com as zonas altimétricas/precipitação, formando as unidades de análise utilizadas para o estudo do escoamento, ou seja, cada unidade básica de escoamento será definida pela relação à capacidade de armazenamento e às condições climáticas.

É importante colocar que a PCD disponibilizará dos dados sobre água disponível do solo, já relacionando os fatores que levam à infiltração e/ou ao escoamento, contudo utiliza o mesmo limite para toda a área. Assim, o presente estudo utilizará os dados obtidos pela PCD e substituirá os limites de água acumulada no solo, utilizando limites diferentes para cada área homogênea. 
Para a mensuração da capacidade de armazenamento de solo, será utilizada a combinação da classe de solo com o tipo de uso, considerando, assim, a porosidade do solo, com o sistema radicular da vegetação e o nível de impermeabilização do mesmo (CHIEW et al., 1995; FENG; VICO; PORPORATO, 2012), resultando em áreas homogêneas definidas a partir da capacidade máxima de armazenamento de água $(\mathrm{mm})$. O comportamento natural de expansão e retração da cobertura vegetal nos ambientes secos, principalmente no domínio tropical, afeta sazonalmente a capacidade de campo devido às alterações na profundidade média das raízes (FENG; VICO; PORPORATO, 2012), contudo, visando a uma simplificação no presente trabalho, tal alteração não foi levada em consideração.

Para identificar a atual configuração do uso/ ocupação do solo o presente trabalho usará como base o mapa de uso do solo elaborado por Souza (2011), que será atualizado a partir de dados de campo obtidos com o auxílio de GPS (GPS Garmim Etrex VistaHcx e o GPS topográfico PRO-XH - Trimble), como também imagens QUICKBIRD atualizadas. Uma das especificidades é usar imagens de diferentes períodos do ano, para que seja possível identificar as diferenças intra-anuais de uso, como a relação cultura de ciclo curto, pasto e solo nu, que ocorre em grande parte das áreas utilizadas na bacia (SOUZA, 2011).

Já para a distribuição dos solos na bacia foi utilizado o mapa desenvolvido por Souza (2013), em que o autor utilizou a carta de solo disponível na escala de 1:100.000 e, a partir de catenas de solo comuns na região (CORRÊA; SOUZA; CAVALCANTI, 2014) e abordagens de mapeamento digital do solo, delimitou a localização de cada tipo de solo presente nas associações de solo disponíveis no mapeamento.

\section{Resultados e discussão}

O mapeamento de uso/cobertura dos solos (Figura 3 - Esquerda) identificou oito classes diferentes, tendo como foco variações que influenciariam a capacidade de armazenamento de água e consequentemente o escoamento, tendo como fatores principais o tipo de vegetação, densidade/conservação da vegetação e impermeabilização. As classes identificadas foram: açudes e lagos; floresta subcaducifólia degradada; vegetação de transição conservada; vegetação de transição degradada; vegetação de caatinga conservada; vegetação de caatinga degradada; uso agrícola misto; e áreas urbanas. 0 valor para zona radicular média; que vai de $120 \mathrm{~cm}$ para as áreas com vegetação de transição conservada até $4 \mathrm{~cm}$ para as áreas urbanas com alto nível de impermeabilização; e a porcentagem da distribuição de cada classe está sumarizada na Tabela 2 . Em relação ao valor, ele foi inicialmente baseado em Alfonsi et al. (1990) e levou em consideração as especificidades locais, tais como as áreas de vegetação degradada, as quais apresentam áreas de solo exposto; como também a própria característica de retração e expansão da vegetação local. Por fim, para as áreas urbanas, baseado no alto grau de impermeabilização, foi definido um baixo valor para a zona radicular média, enquanto que para as áreas com corpos d'água não foi calculado o escoamento, e desse modo não foi analisado. Quanto à espacialização, observa-se a predominância de áreas de uso agrícola misto, caracterizada pela modificação intra-anual de usos (tal como milho/feijão, pasto, canade-açúcar e solo exposto), com 49,34\% concentrados especialmente nas áreas mais altas da bacia. Outra classe predominante é a de vegetação de caatinga conservada, com $21,25 \%$ da área da bacia, concentrados na parte central.

Tabela 2 - Zona radicular média para as classes de uso/cobertura do solo.

\begin{tabular}{ccc}
\hline Classe & Zona radicular média (cm) & Ärea (\%) \\
\hline $\begin{array}{c}\text { Açudes e lagos } \\
\text { Vegetação de transição } \\
\text { conservada }\end{array}$ & 120 & 5.01 \\
\hline $\begin{array}{c}\text { Caatinga conservada } \\
\text { Floresta subcaducifólia } \\
\text { degradada }\end{array}$ & 100 & 6.71 \\
\hline $\begin{array}{c}\text { Vegetação de transição } \\
\text { degradada }\end{array}$ & 75 & 21.25 \\
\hline Caatinga degradada & 60 & 4.83 \\
Uso agricola misto & & 2.56 \\
\hline Area urbana impermeabilizada & 50 & 7.61 \\
\hline
\end{tabular}


Figura 3 - Esquerda - Mapa de uso/cobertura do solo (atualizado de Souza, 2011). Direita - Textura dos tipos de solo da Bacia do Riacho do Saco (adaptado de Souza, 2013).

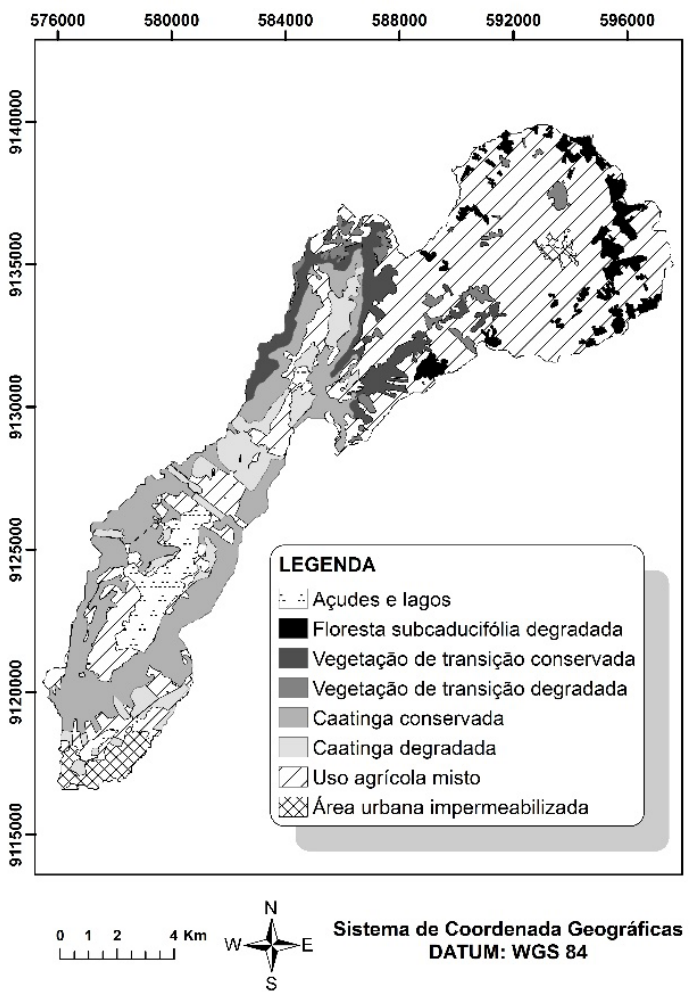

A partir do mapeamento de solos (Souza, 2013), os solos foram agrupados em três classes, solos arenosos, médios e argilosos (Figura 3 - Direita), além dos afloramentos rochosos; posteriormente foi definido o CAD médio para cada uma das classes (Tabela 3). As informações sobre a textura dos solos advêm do Levantamento de Reconhecimento de Baixa e Média Intensidade dos Solos do Estado de Pernambuco

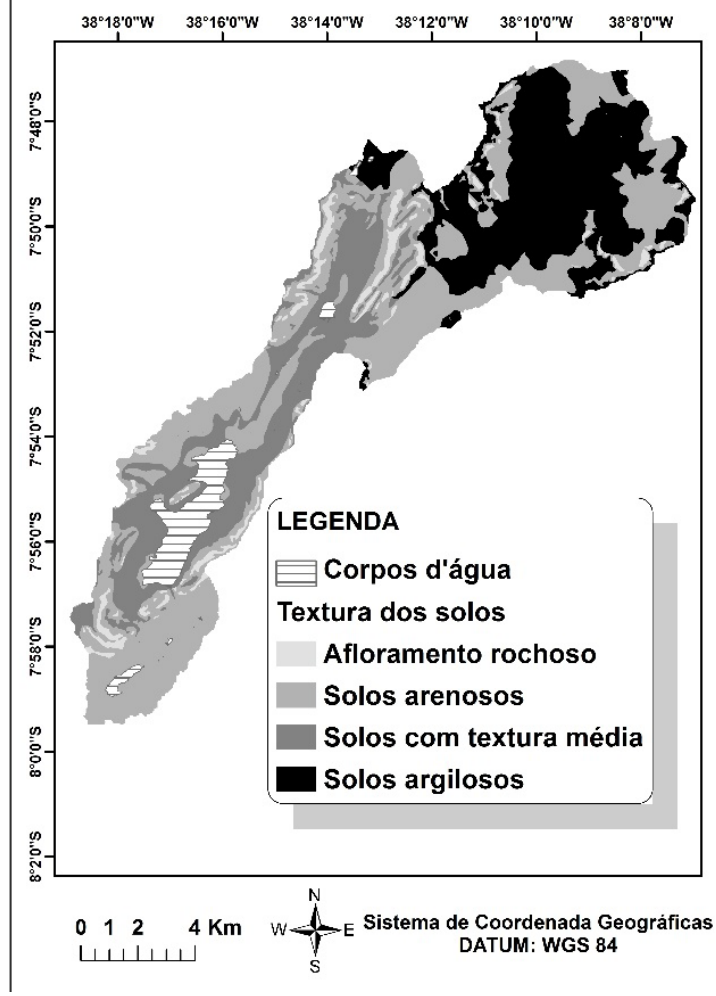

(Embrapa, 2000). Assim, nas áreas de afloramento, os planossolos, luvissolos e neossolos litólicos foram agrupados nos solos arenosos; os argissolos vermelhoamarelo e cambissolos apresentam textura média; e, por fim, os argissolos vermelhos, argissolos amarelos, gleissolos e neossolos flúvicos foram agrupados como solos argilosos, além dos cambissolos presentes nas áreas altas da bacia.

Tabela 3 - CAD médio e distribuição dos tipos de solo (adaptado de Doorenbos e Kassam, 1994).

\begin{tabular}{c|c|c}
\hline & CAD médio $(\mathrm{mm} / \mathrm{cm})$ & Area $(\%)$ \\
\hline Afloramentos rochosos & 0,2 & 4,6 \\
\hline Solos arenosos & 0,6 & 45,7 \\
\hline Solos com textura & & \\
média & 1,4 & 20,1 \\
\hline Solos argilosos & 2 & 29,6
\end{tabular}


Avaliando a distribuição dos solos na bacia, é visível a concentração dos solos argilosos nas partes mais altas da bacia, locais onde, devido aos solos mais profundos, há o intenso uso agrícola. Por outro lado, os solos arenosos se concentram nos pontos mais baixos da bacia e nas áreas com alta declividade, sendo comum a presença de áreas de vegetação conservada. Apesar da baixa ocorrência dos afloramentos rochosos $(4,6 \%)$, as áreas foram incluídas pela grande diferenciação do comportamento do escoamento para estas áreas, e desse modo foi incluída a classe de afloramentos rochosos com CAD médio de $0,2 \mathrm{~mm} / \mathrm{cm}$, visto que entre e até sobre os afloramentos são comuns pequenas áreas com a presença de solo e marmitas de dissolução.

Posteriormente, as informações sobre uso/cobertura do solo e sobre a textura dos solos foram transformadas em dois arquivos Raster, sendo assim possível através de Álgebra de Mapas, utilizando a ferramenta Raster Calculation da extensão Spatial Analyst Tools do ArcGis 10.1, multiplicar a Zona Radicular Média (Zr) pelo CAD médio dos solos (n), e deste modo gerar o Raster do CAD máximo. Devido à complexidade da organização ambiental da bacia, foram obtidos 22 valores, indo de $2 \mathrm{~mm}$ até $240 \mathrm{~mm}$; contudo, boa parte dos valores apresentou distribuição ínfıma na bacia, em especial os valores extremos. Visando simplificar a análise, as áreas foram agrupadas pelos valores "médios" mais frequentes, resultando em sete valores $(10 \mathrm{~mm}$, $20 \mathrm{~mm}, 50 \mathrm{~mm}, 70 \mathrm{~mm}, 100 \mathrm{~mm}, 120 \mathrm{~mm}$ e $150 \mathrm{~mm}$ ). As áreas com CAD $10 \mathrm{~mm}$ e $20 \mathrm{~mm}$ são controladas pelas áreas impermeabilizadas e pelas áreas de afloramento rochoso; enquanto que as áreas com $120 \mathrm{~mm}$ e $150 \mathrm{~mm}$ são definidas pela presença de vegetação associada a solos de textura argilosa.

Definidos os valores do CAD máximo, as áreas homogêneas foram separadas a partir das quatro zonas de precipitação existentes na bacia (Figura 2); assim, foram identificadas 24 zonas homogêneas de "CAD máximo/zona climática" (Figura 4). Uma zona homogênea seria uma área que apresenta a mesma resposta de capacidade de campo, resultado das características pedológicas e de cobertura da terra, e que estejam na mesma zona de precipitação. As zonas de precipitação foram separadas por letras, cada qual representando uma área a partir dos dados de uma PCD (Figura 2), sendo: A - PCD Serra Talhada INMET; B - PCD Serra Talhada LAMEPE/ITEP; C - PCD Santa Cruz da Baixa Verde; D - PCD Triunfo. Ou seja, a zona homogênea D70 representa as áreas cuja capacidade de campo é de $70 \mathrm{~mm}$ e que está submetida à zona de precipitação monitorada pela PCD Triunfo.

As zonas homogêneas de maior relevância espacial para a bacia são a C70 (18,77\% da bacia), B50 (17,04\%), D70 (10,28\%) e D20 (9,98\%); essas quatro zonas representam cerca de $56,6 \% \%$ da área total da bacia. Por outro lado, oito das zonas homogêneas (B240, B10, D240, A150, D100, C10, C240, D10) não ultrapassam 1\% da área da bacia cada.

Tendo as zonas homogêneas como referência, foi realizado o cálculo do Balanço Hídrico Sequencial Diário, para o período 2006-2012, para cada uma das áreas separadamente, modificando o valor do CAD para cada área, obtendo deste modo o resultado das informações detalhadas e espacializadas sobre precipitação e escoamento para a Bacia do Riacho do Saco. Sendo que as informações relativas ao volume de chuva e de escoamento foram calculadas em "mm" (profundidade

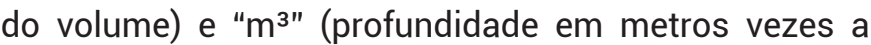
área em metros ${ }^{2}$ ). As informações foram sumarizadas na Tabela 4.

Figura 4 - Zonas homogêneas de CAD máximo e faixa altimétrica. A legenda foi organizada pelo código de uma letra e um número, em que a letra representa a zona de precipitação e o número o CAD máximo. Zonas de precipitação: A - PCD Serra Talhada INMET; B - PCD Serra Talhada LAMEPE/ITEP; C - PCD Santa Cruz da Baixa Verde; D - PCD Triunfo. CAD máximo: $10 \mathrm{~mm}$ (tons de cinza); $20 \mathrm{~mm}$ (tons de vermelho); $50 \mathrm{~mm}$ (tons de laranja), $70 \mathrm{~mm}$ (tons de verde); $100 \mathrm{~mm}$ (tons de azul); $120 \mathrm{~mm}$ (tons de lilás); $150 \mathrm{~mm}$ (tons de marrom). 
Figura 4 - Zonas homogêneas de CAD máximo e faixa altimétrica. A legenda foi organizada pelo código de uma letra e um número, em que a letra representa a zona de precipitação e o número o CAD máximo. Zonas de precipitação: A - PCD Serra Talhada INMET; B - PCD Serra Talhada LAMEPE/ITEP; C - PCD Santa Cruz da Baixa Verde; D - PCD Triunfo. CAD máximo: 10mm (tons de cinza); $20 \mathrm{~mm}$ (tons de vermelho); $50 \mathrm{~mm}$ (tons de laranja), $70 \mathrm{~mm}$ (tons de verde); 100mm (tons de azul); $120 \mathrm{~mm}$ (tons de lilás); $150 \mathrm{~mm}$

(tons de marrom).

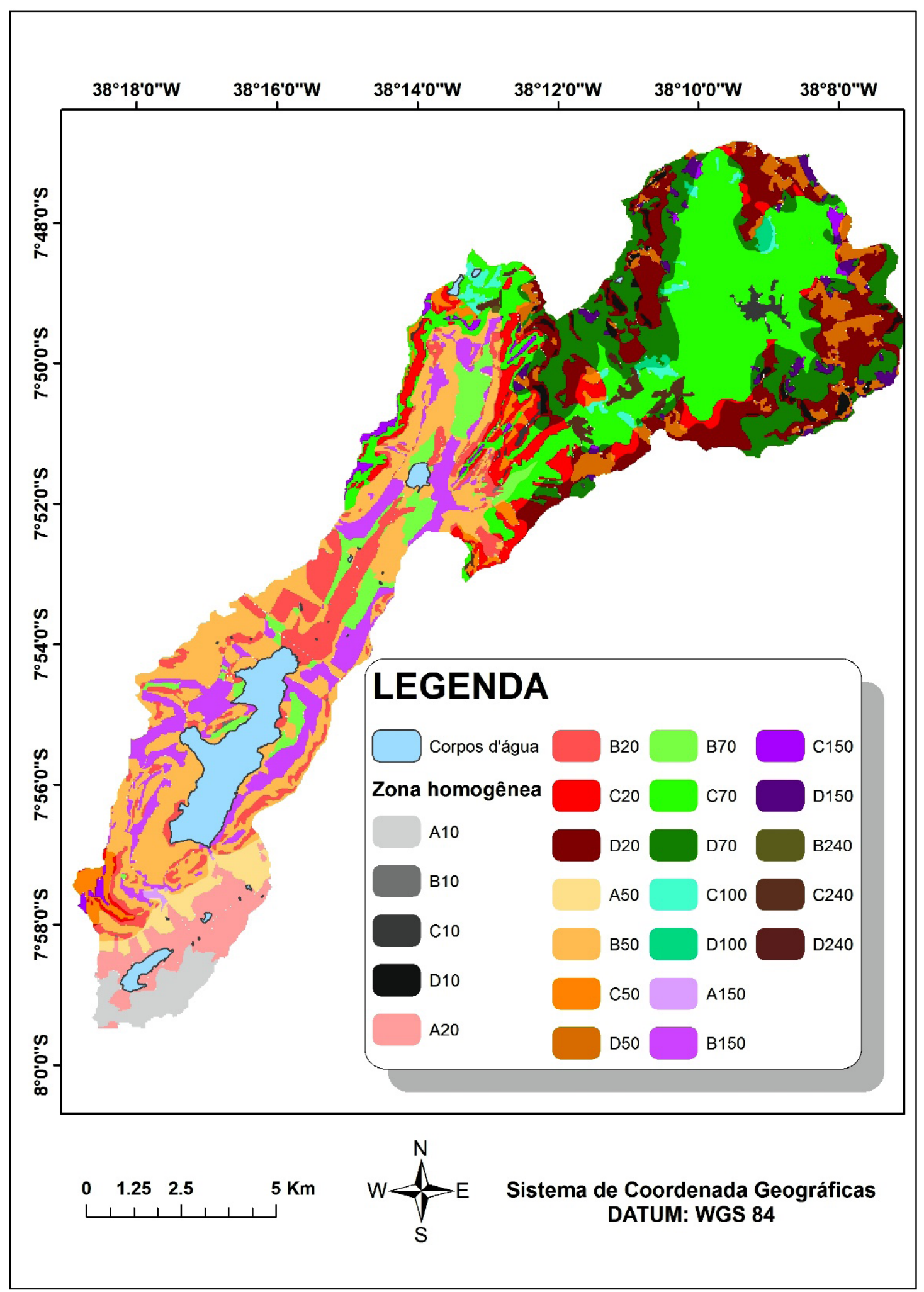


Tabela 4 - Dados de precipitação e escoamento para cada zona da bacia. Esc_tot - escoamento total para cada zona homogênea entre 2006-2012; Vol_esc - volume de escoamento em $\mathrm{m}^{3}$ entre 2006-2012; Vol_esc_ZH_bac_\% - porcentagem do volume de escoamento de cada zona altimétrica em relação ao volume total de escoamento da bacia; Vol_esc_tot_\% - porcentagem do volume de escoamento de cada zona homogênea em relação ao volume total de escoamento da bacia.

\begin{tabular}{|c|c|c|c|c|c|}
\hline $\mathrm{ZH}$ & Area_tot_s & Volpre_tot_k & Pre_tuto_f & Vol_test_ZH_bat_\% & Vol_teto_tot_s \\
\hline A10 & $2,34 \%$ & $1,85 \%$ & 58,456 & $6,09 \%$ & $2,35 \%$ \\
\hline$A 20$ & $3,87 \%$ & $3,07 \%$ & 50,728 & $6,09 \%$ & $3,37 \%$ \\
\hline ABO & $1,95 \%$ & $1,54 \%$ & $34,43 \%$ & $6,09 \%$ & $1,15 \%$ \\
\hline A150 & $0,12 \%$ & $0,09 \%$ & 11,708 & 6,094 & $0,02 \%$ \\
\hline B10 & 0,058 & 0,048 & $58,99 \%$ & $22,44 \%$ & $0,05 \%$ \\
\hline 820 & $6,96 \%$ & $570 \%$ & $52,11 \%$ & $22,44 \%$ & $6,43 \%$ \\
\hline BEO & 17,048 & 13,958 & $37,73 \%$ & $22,44 \%$ & 11,405 \\
\hline 870 & 3,978 & $3,25 \%$ & $30,69 \%$ & $22,44 \%$ & $2,16 \%$ \\
\hline B160 & 7,598 & $6,22 \%$ & 17,718 & $22,44 \%$ & $2,36 \%$ \\
\hline$B 240$ & 0,008 & 0,028 & $10,43 \%$ & $22,44 \%$ & $0,01 \%$ \\
\hline Cilo & 0,649 & $0,69 \%$ & 69,855 & $24,36 \%$ & $0,90 \%$ \\
\hline $\mathrm{C20}$ & $4,87 \%$ & 4,528 & $61,64 \%$ & $24,36 \%$ & $6,04 \%$ \\
\hline C50 & $2,01 \%$ & $1,87 \%$ & $44,89 \%$ & $24,36 \%$ & $1,82 \%$ \\
\hline c70 & $10,77 \%$ & $17,44 \%$ & $37,66 \%$ & $24,36 \%$ & 14,225 \\
\hline 0100 & 1,028 & $0,95 \%$ & $30,49 \%$ & $24,36 \%$ & $0,65 \%$ \\
\hline C150 & $1,00 \%$ & 0,908 & $23,91 \%$ & $24,36 \%$ & $0,46 \%$ \\
\hline 0240 & $0,86 \%$ & $0,80 \%$ & $16,43 \%$ & $24,36 \%$ & $0,20 \%$ \\
\hline Dilo & $0,95 \%$ & 1,314 & $76,96 \%$ & 46,31 है & $2,17 \%$ \\
\hline 020 & $9,90 \%$ & $13,77 \%$ & $70,05 \%$ & $46,31 \%$ & 20,895 \\
\hline D50 & $3,00 \%$ & $5,24 \%$ & $5,07,07 \%$ & 46,31 के & $6,25 \%$ \\
\hline D70 & $10,28 \%$ & $14,18 \%$ & $48,30 \%$ & 46,31 के & 14,805 \\
\hline 0100 & 0,448 & 0,618 & $46,09 \%$ & 46,31 है & $0,61 \%$ \\
\hline D150 & 1,368 & $1,87 \%$ & $36,39 \%$ & $46,31 \%$ & $1,46 \%$ \\
\hline$[240$ & 0,118 & 0,168 & $29,64 \%$ & $46,31 \%$ & $0,10 \%$ \\
\hline
\end{tabular}

Deste modo, ao comparar o percentual de área espacial com o percentual do volume de chuva observase o crescimento da importância da zona altimétrica da PCD Triunfo, que, apesar de representar apenas $25,6 \%$ da área da bacia, é responsável por mais de $37 \%$ do volume de água captado pela bacia, alcançando $46,31 \%$ do volume escoado em toda a bacia. Desse modo, observa-se que, devido ao maior nível de precipitação nas cabeceiras da bacia, área da PCD Triunfo, essas áreas representam a principal fonte de captação de água para a bacia.
Obviamente, a resposta do escoamento exibe uma relação inversamente proporcional ao valor de CAD máximo, ou seja, quanto menor o CAD máximo, maior a porcentagem da precipitação que escoa. Ao mesmo tempo, o percentual escoado aumenta quando há um aumento dos eventos de chuva e totais de precipitação, como pode ser visto, por exemplo, nas porcentagens para as áreas da PCD Triunfo, que apresentam valores maiores para todos os níveis de CAD máximo em relação às outras áreas. Para exemplificar, podem-se citar as áreas com CAD 10 e com CAD 150; enquanto que Serra Talhada INMET (zona altimétrica "A") apresenta 58,4\% e 
11,8\%, respectivamente, Triunfo (zona altimétrica "D") chega a $76,4 \%$ para o CAD de $10 \mathrm{~mm}$ e $29,64 \%$ para o CAD de $240 \mathrm{~mm}$. Tal fator, em conjunto com o maior volume de precipitação e menor temperatura (menor evapotranspiração potencial), potencializa a importância do patamar de Triunfo para o total de escoamento da bacia, indo ao encontro das afirmações anteriores. 0 que também fica claro ao se observar a Figura 5 - Esquerda, na qual é visível a concentração dos valores mais altos na área da PCD Triunfo (as áreas mais altas da bacia, acima de $900 \mathrm{~m}$ de altitude); enquanto que no resto da bacia os índices mais altos, acima de $48,3 \%$, ficam restritos a encostas com altas declividades. Pode-se observar como exceções o extremo sul da bacia, que apresenta índice superior a $50 \%$ de precipitação escoada e é controlada pela presença da mancha urbana e de expansão urbana (novos loteamentos) de Serra Talhada, e algumas manchas de uso agrícola em solos arenosos rasos na parte central da bacia.

Figura 5 - Direita, que apresenta a distribuição do escoamento total em $\mathrm{mm}$, torna clara a concentração do maior volume de escoamento na parte superior da bacia, estando as classes mais altas de escoamento total quase que exclusivamente inseridas na região da PCD Triunfo, valores acima de $2.607 \mathrm{~mm}$ para o período analisado. Por outro lado, as áreas de Serra Talhada foram as que apresentaram menor volume de escoamento total, em especial nas áreas com caatinga conservada, valores abaixo de $792 \mathrm{~mm}$. Em relação ao detalhamento de cada zona homogênea, há a predominância das zonas homogêneas D20 e D70, participando com $20,89 \%$ e $14,83 \%$, respectivamente, do volume total de escoamento da bacia. No caso da zona D20, comparando a participação da mesma na área da bacia $(9,98)$ e no percentual de volume de precipitação captado (13,77\%), há um acréscimo em relação ao percentual do volume escoado total $(20,98 \%)$ de $109 \%$ e $52 \%$, respectivamente. Vale lembrar que o volume escoado está diretamente ligado à energia disponível para erosão, produção de sedimentos e transporte de sedimentos, ou seja, quanto maior o nível de escoamento, maior é a possibilidade de haver erosão e transporte de sedimento.

Figura 5 - Esquerda - Percentual médio de precipitação escoada entre os anos de 2006 e 2012 para a Bacia do Riacho do Saco. Direita - Escoamento total em mm entre os anos de 2006 e 2012 para a Bacia do Riacho do Saco.
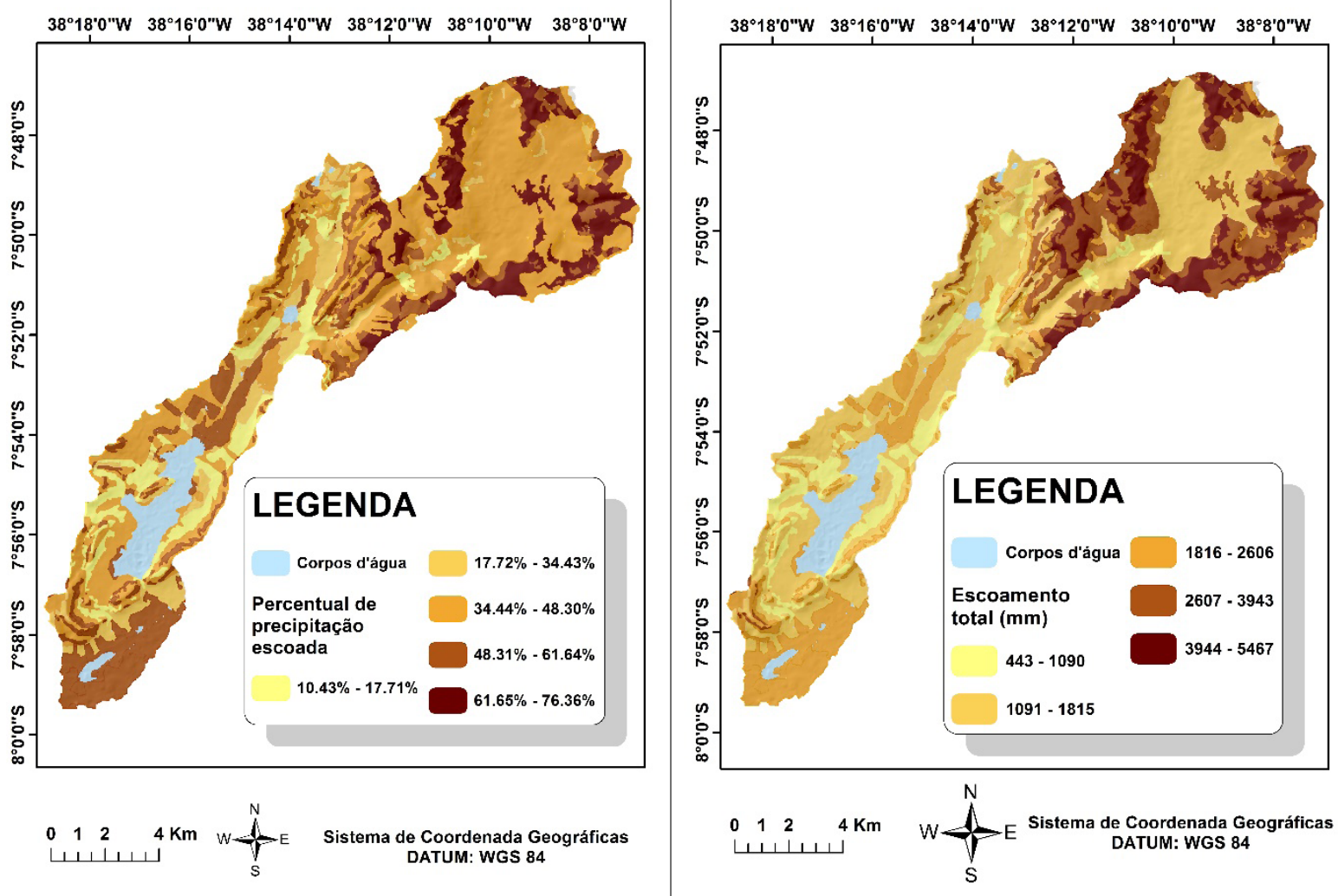


\section{Considerações finais}

Os resultados apontam para a grande influência das áreas das serras subúmidas do semiárido nordestino, regionalmente chamadas de "brejos de altitude" (Melo, 1988), na captação de água para a rede de drenagem sertaneja, tendo como principal característica as chuvas orográficas. Devido a este fator, os brejos de altitude foram áreas preferenciais de ocupação no sertão nordestino, o que gerou intensa degradação da vegetação nativa e generalização do uso agrícola. Isso pode ser observado na Figura 3 - Esquerda, em que a parte superior da bacia apresenta predominantemente uso agrícola, bem como a inexistência de áreas de floresta subcaducifólia conservada, apenas as áreas que apresentam alta declividade ou com afloramentos rochosos, dificultando/impossibilitando o uso agrícola, e que ainda apresentam floresta, mesmo que degradada. Desse modo, as mudanças antrópicas levam à diminuição generalizada do CAD máximo dessas áreas, diminuindo o volume de água infiltrada e aumentando o escoamento.

Assim, é necessário avaliar a captação de água de dois modos, como água superficial/escoada e água subsuperficial infiltrada/percolada. Inicialmente, a água escoada vai se deslocar na paisagem de maneira mais rápida em direção aos canais até chegar aos reservatórios ou sair do sistema; no caso dos ambientes secos, como é o caso da bacia estudada, é prejudicial para as comunidades a remoção rápida da água, sendo necessária a construção de diversos pequenos barramentos, inclusive em canais de ordem zero. Contudo, o acúmulo de água nos reservatórios superficiais é deficitário, visto o alto valor da evaporação potencial, chegando a mais de $1.500 \mathrm{~mm} / \mathrm{ano}$. Ao mesmo tempo, devido ao caráter subcaducifólio/caducifólio da vegetação encontrada, em conjunto com plantações temporárias mistas, em que no início do período chuvoso o solo encontra-se exposto (Guerra, 2004), a presença de processos erosivos é intensa, podendo gerar desde perda de capacidade produtiva até voçorocamento nas áreas com manto de alteração mais profundo. Os dados mostram que em duas áreas com parâmetros físicos homogêneos, clima e solo, havendo a substituição da vegetação nativa por uso agrícola, isso gera um aumento de mais de $50 \%$ do volume escoado médio, chegando a casos de o aumento ser superior a $80 \%$, como é o caso de zonas homogêneas C100 e C240 (respectivamente, solo argiloso+uso agrícola, e solo argiloso+vegetação de transição conservada).

Por outro lado, o volume de precipitação que infiltra se desloca na paisagem como fluxo de base, chegando mais lentamente aos canais e represamentos; vale lembrar que nos ambientes secos de natureza cristalina a percolação profunda para recarga de aquíferos é extremamente baixa, podendo ser desconsiderada (Caylor; Manfreda; Iturbe, 2005). Há, também, a água que fica "represada" nos aquíferos aluviais e representa um recurso-chave para a gestão dos recursos hídricos em ambientes secos (Love et al., 2011), o que pode ser visto na área, em especial na área de Santa Cruz da Baixa Verde, onde a maior parte da população rural é abastecida a partir de poços na zona aluvial, os chamados poços amazonas.

Desse modo, torna-se clara a necessidade do aumento da captação e da retenção da água através da infiltração e do fluxo de base, para desta maneira haver uma menor perda de água na bacia, seja por evaporação ou por escoamento rápido. Devido à inexistência de dados fluviométricos para a área, problema comum para o semiárido nordestino (especialmente para pequenas bacias), o Balanço Hídrico Sequencial Diário demonstrouse uma ferramenta imprescindível e adequada para a análise da relação precipitação/escoamento.

\section{Agradecimento}

A realização do trabalho só foi possível devido ao financiamento da Fundação de Amparo à Ciência e Tecnologia do Estado de Pernambuco - FACEPE. 


\section{Referências}

ALFONSI, R. R. et al. (1990). Métodos agrometeorológicos para controle da irrigação. Campinas: Instituto Agronômico. ARAI, F. K.; PEREIRA, S. B.; GONÇALVES, G. G. G. (2012). Characterization of water availability in a hydrographic basin. Engenharia Agrícola, v. 33, n. 3, p. 581-601.

BESKOW, S. et al. (2009). Estimativa do escoamento superficial em uma bacia hidrográfica com base em modelagem dinâmica e distribuída. Revista Brasileira de Ciências do Solo, v. 33, p. 169-178.

BIGARELLA, J. J.; SUGUIO, K.; BECKER, R. D. (1979). Ambiente fluvial: ambientes de sedimentação, sua interpretação e importância. 1. ed. Curitiba: Editora da Universidade Federal do Paraná. Associação de Defesa e Educação Ambiental.

BRACKEN, L. J.; CROKE, J. The concept of hydrological connectivity and its contribution to understanding runoffdominated geomorphic systems. Hydrol. Process. 21, 1.749-1.763 (2007).

BURT, T. P. (2001). Integrated management of sensitive catchment systems. Catena, v. 42, p. 275-290.

CANDIDO, D. H.; NUNES, L. H. (2008). Influência da orografia na precipitação da área entre o vale do rio Tietê e a serra da Mantiqueira. GEOUSP, n. 24, p. 8-27.

CAYLOR, K. K.; MANFREDA, S.; ITURBE, I. R. (2005). On the coupled geomorphological and ecohydrological organization of the river basin. Advances in Water Resources, v. 28, p. 69-86.

CHIEW, F. H. S. et al. (1995). Simulation of the impacts of climatic change on runoff and soil moisture in Australian catchments. Journal of Hydrology, n. 167, p. 121-147.

COLTON, D. E. (1976). Numerical Simulation of the orographically induced precipitation distribution for use in hydrologic analysis. Journal of applied meteorology, v. 15, n. 12, p. 1.241-1.251.

CORRADINI, C. (1985). Analysis of the effects of orography on surface rainfall by a parameterized numerical model. Journal of Hydrology, n. 77, p. 19-30.

CORRÊA, A. C. B. (1997). Mapeamento geomorfológico de detalhe do maciço da Serra da Baixa Verde, Pernambuco: estudo da relação entre a compartimentação geomorfológica e a distribuição dos sistemas geoambientais. Dissertação (Mestrado). Universidade Federal de Pernambuco, Programa de Pós-Graduação em Geografia. Recife.

CORRÊA, A. C. B. et al. (2012). Megageomorfologia e morfoestrutura do Planalto da Borborema. Revista do Instituto Geológico, n. 31 (1/2), p. 35-52.

CORRÊA, A. C. B.; SOUZA, J. O. P.; CAVALCANTI, L. C. S. (2014). Solos do ambiente semiárido brasileiro: erosão e degradação a partir de uma perspectiva geomorfológica. In: GUERRA, A. J. T.; JORGE, M. C. O. Degradação dos solos no Brasil. Rio de Janeiro: Bertrand Brasil, p. 127-169.

COSTA, C. F. G. et al. (2013). Escoamento superficial em Latossolo Amarelo distrófico típico sob diferentes agroecossistemas no nordeste paraense. Revista Brasileira de Engenharia Agrícola e Ambiental, v. 17, n. 2, p. 162-169.

DOORENBOS, J.; KASSAM, A. H. (1994). Efeito da água no rendimento das culturas. Campina Grande: UFPB.

EMBRAPA. Zoneamento Agroecológico do Estado de Pernambuco - ZAPE. Recife: Embrapa Solos/Governo do Estado de Pernambuco - Secretaria de Produção Rural e Reforma Agrária, 2001. CD-ROM. (Embrapa Solos. Documentos, 35), 2001.

FEITOSA, A. et al. (2010). Modelagem dinâmica de escoamento superficial influenciando a susceptibilidade à erosão dos solos num município do semiárido de Pernambuco. Revista Brasileira de Geomorfologia, v. 11, n. 2, p. 75-82.

FENG, X.; VICO, G.; PORPORATO, A. (2012). On the effects of seasonality on soil water balance and plant grownth. Water Resources Research, v. 48, p. 1-12.

GRAF, W. L. (1988). Fluvial Process in Dryland Rivers. Caldwell: The Blackburn Press. 
GUERRA, A. J. T. (2004). Geomorfologia aplicada: algumas reflexões. In: SANTOS, J. M.; FARIAS, M. Reflexões e construções geográficas contemporâneas. Salvador: Grasb, p. 144-161.

HIGGINS, D. A. et al. (1988). Calibration of a water-balance model for small watersheds in Eastern Oregon. Water Resources Bulletin, v. 2, n. 2, p. 347-360.

IMESON, A. C.; PRINSEN, H. A. M. (2004). Vegetation patterns as biological indicators for identifying runoff and sediment source and sink areas for semi-árid landscapes in Spain. Agricultue, Ecosystems and Environment, v. 104, p. 333-342.

ITURBE, I. R. et al. (1999). On the spatial and temporal links between vegetation, climate, and soil moisture. Water Resources Research, v. 35, n. 12, p. 3.709-3.722.

KARNIELE, A.; ASHER, J. B. (1993). A daily runoff simulation in semi-arid watersheds based on soil water deficit calculations. Journal of Hydrology, n. 149, p. 9-25.

KASAI, M. et al. (2005). Impacts of land use change on patterns of sediment flux in Weraamaia catchment, New Zealand. Catena, v. 64, p. 27-60.

LIANG, Z. et al. (2012). A statistically based runoff-yield model coupling infiltration excess and saturation excess mechanisms. Hydrological Processes, v. 26, p. 2.856-2.865.

LOVE, D. et al. (2011). A water balance modelling approach to optimising the use of water resources in ephemeral sand rivers. River Research and Applications, v. 27, p. 908-925.

LOVELL, S. T.; JOHNSTON, D. M. (2009). Designing landscape for performance based on emerging principles in landscape ecology. Ecology and Society, v. 14 (1) : 44.

MACHADO, R. E.; VETTORAZZI, C. A.; CRUCIANI, D. E. (2003). Simulação de escoamento em uma microbacia hidrográfica utilizando técnicas de modelagem e geoprocessamento. Revista Brasileira de Recursos Hídricos, v. 8, n. 1, p. 147-155.

MELO, M. L. (coord). (1988). Áreas de exceção da Paraíba e dos sertões de Pernambuco. Recife: SUDENE-PSU-SER, $321 p$.

MICHAELIDES, K.; WILSON, M. D. (2007). Uncertainty in predicted runoff due to patterns of spatially variable infiltration. Water Resources Research, v. 43, p. 1-14.

PAN, X. et al. (2013). Hillslope-scale probabilistic characterization of soil moisture dynamics and average water balance. Hydrological Processes, v. 27, p. 1464-1474.

RAMOS, M. C.; CASANOVAS, J. A. M. (2006). Impact of land levelling on soil moisture and runoff variability in vineyards under different rainfall distributions in Mediterranean climate and its influence on crop productivity. Journal of Hydrology, n. 321, p. 131-146.

RODRIGUES, J. O. et al. (2013). Respostas hidrológicas em pequenas bacias na região semiárida em função do uso do solo. Revista Brasileira de Engenharia Agrícola e Ambiental, v. 17, n. 13, p. 312-318.

SOUZA, J. O. P. (2011). Sistema fluvial e açudagem no semiárido, relação entre a conectividade da paisagem e dinâmica da precipitação, na bacia de drenagem do riacho do Saco, Serra Talhada, Pernambuco. Dissertação (Mestrado) Universidade Federal de Pernambuco. Programa de Pós-Graduação em Desenvolvimento e Meio ambiente. Recife. $169 p$.

SOUZA, J. O. P. de (2013). Catenas e detalhamento expedito dos solos da Bacia do Riacho do Saco - Serra Talhada/ Pernambuco. Geosul, v. 28, n. 56, p. 163-182.

TUCCI, C. E. M.; CLARKE, R. T. (1997). Impactos das mudanças da cobertura vegetal no escoamento: revisão. Revista Brasileira de Recursos Hídricos, v. 2, n. 1, p. 135-15. 